\title{
The stability of binocular rivalry during spaced and massed viewing'
}

ROSEMARY COGAN ${ }^{2}$ AND ALVIN G. GOLDSTEIN

UNIVERSITY OF MISSOURI
The purpose of the study was consideration of the stability of binocular rivalry rates during extended periods of spaced and massed viewing by untrained observers. In Experiment I no relationship was found between eyeblink rates and rivalry rates, and a visual vigilance task reported simultaneously with rivalry reporting proved to be a useful indicator that Ss maintained attention during the viewing period; the vigilance task did not disnupt rivalry data. In Experiment II Ss reported rivalry during $10 \mathrm{~min}$. of continuous or $10 \mathrm{~min}$. of non-continuous viewing on each of three consecutive days. The vigilance task was presented to all Ss. After the first minute of viewing, during which conditions were alike for all $S$ s and rivalry rates differed only slightly, the rates of the Spaced Groups increased while the rates of the Massed Groups showed little variation.

Research in binocular rivalry has been largely confined to investigation of stimulus variables affecting the rate of rivalry changes (summarized by Levelt, 1965). Basic inquiry into the nature of rivalry itself has received less attention. Several researchers, however, have noted that rivalry rates seem to vary as a function of the viewing time. Alexander and Bricker (1952) reported a decrease in rate over $25 \mathrm{~min}$. of non-continuous viewing. Among their five Ss they found some tendency for the most extensive decreases to occur in Ss with high initial rates. Platz, Uhr, and Miller (1960) reported a $16 \%$ greater decrease in rate between two non-consecutive $1 \mathrm{~min}$. viewing periods for Ss under the influence of meprobamate as compared with the decrease shown by placebo Ss. Goldstein and Cofoid (1965) observed most frequently a decrease in rate during three consecutive minutes of viewing by college Ss, and a tendency towards increased rates during interrupted viewing. Aafjes, Hueting, and Visser (1966) found an increase in rate during interrupted viewing periods and essentially no rate change during continuous viewing periods. Washburn and Gillette (1933) suggest that rivalry rate may increase as the rate of eyeblinks increases. Since it is possible that eyeblink frequency increases during the rather demanding period of viewing, this notion could explain changes in rivalry rate across time.

It is apparent that there is disagreement in the literature concerning the stability of rivalry rates over time. This study was designed to examine the stability of rivalry rates during extended periods of continuous and non-continuous viewing. The possibility that the sustained attention required in the rivalry task might result in some change in rate of eyeblinks and thereby in some change in rivalry rate was examined. The possibility that the degree to which Ss attend to the task may fluctuate during the viewing period, producing fluctuation in reported rivalry rates, was also examined.

\section{EXPERIMENT I}

The purposes of Experiment I were (a) to examine the stability of rivalry rate during $10 \mathrm{~min}$. of massed viewing; (b) to determine whether there is any relationship between rivalry rate and rate of eyeblinks; and (c) to determine whether a decrease in rivalry rate is associated with a decrease in the accuracy of reporting a visual vigilance task in such a manner as to suggest that decreases in rivalry rate may be due to lessening of attention by Ss.

\section{Method}

Subjects. Eleven male and 12 female students in introductory psychology classes served as Ss. Ss were selected who did not wear corrective lenses, were aware of no visual difficulties, and were naive to the rivalry situation.

Stimulus. The rivalry stimulus consisted of a left and right black fusion square, $86 \mathrm{~mm}$ apart, each subtending $2.1^{\circ}$ at the retina. Within these fusion squares a $1.6^{\circ}$ black vertical line was centered in the right stimulus-half, and an identical horizontal line in the left stimulus-half. A pinhole in the center of each fusion square provided both a central fixation point and openings through which point light sources were positioned. The intensity of the light sources was adjusted before the experiment so that two trained observers reported $80 \%$ of all light flashes occurring during a $5 \mathrm{~min}$. test interval during which they were also reporting rivalry.

Apparatus and procedure. Each $S$ entered the electrically shielded experimental chamber and was seated before a Keystone Telebinocular. This instrument was modified by the addition of a cardboard cover encasing the rear of the instrument, restricting the illumination to the light from eight battery powered $3-W$ bulbs, replacing the usual $25-W, 110-V$ bulb in the Telebinocular. The stimulus was placed at the instrument's far point, $23 \mathrm{~cm}$ from the lens, and the reflected light measured at the lens by a Gossen LunaSix meter was approximately 11. Eyeblinks were continuously recorded on the paper write-out of a 
physiograph during testing. Skin electrodes were attached with tape above and below Ss right eye. Also recorded on the remaining channels of the physiograph were the following responses: $S$ depressed a telegraph key with his right hand to indicate visibility of the horizontal line alone, $\mathrm{S}$ depressed another telegraph key with his left hand to indicate visibility of the vertical line alone, and $S$ depressed both telegraph keys to indicate visibility of both lines. In order to familiarize $S s$ with the telegraph key responding, each $S$ was directed to make practice responses to samples of the three possible figures drawn onto $5 \times 7$ cards and presented at the right of the Telebinocular. The responses were practiced until $S$ was responding accurately and automatically to the practice cards.

Ss were divided randomly by sex into a vigilance and a non-vigilance group. Ss in the vigilance group were instructed to depress a third telegraph key, located on the floor, to report the onset of a dim flash of light in the center of the stimulus. The vigilance light was presented at irregular intervals, on the average every $30 \mathrm{sec}$. All Ss were directed to fixate upon the central dot in the stimulus, and were cautioned that the task was demanding. Ss were stopped after $10 \mathrm{~min}$. of reporting and were questioned as to any difficulties that might have occurred.

In summary, in Experiment I two groups of Ss viewed a rivalry stimulus for 10 uninterrupted min. The Ss in the vigilance group were instructed to report by a key press the onset of a small central light. Eyeblinks were recorded from both groups and Ss in both groups reported by appropriate key presses when either the left, right, or both eye stimuli were visible.

\section{Results and Discussion}

Rivalry data were examined in terms of the traditional "number of cycles" measurement, i.e.s the response sequence horizontal $(H)$, vertical $(V)$, hori$z$ ontal would be scored as a single cycle. This system of measuring rivalry did not tally those instances where the left and right stimuli were seen simultaneously, i.e., both (B), but this event does occur with relatively high frequency. Furthermore, the noncyclical changes in perception are not counted by this method. That is, the sequence $\mathrm{H}, \mathrm{V}, \mathrm{B}, \mathrm{V}, \mathrm{B}, \mathrm{H}$ would be scored as only one cycle, but there were five perceptual changes reported. For this rea son a "number of changes" measurement was also considered. Number of cycles, number of changes, number of eyeblinks, and number of vigilance task errors for the vigllance Ss were counted for each successive $30 \mathrm{sec}$. of viewing for 20 Ss. Data from two Ss unable to report rivalry changes and one $S$ who reported the vigilance light more than twice as frequently as it was presented were discarded.

The average Pearson product-moment correlation between the number of cycles and the number of

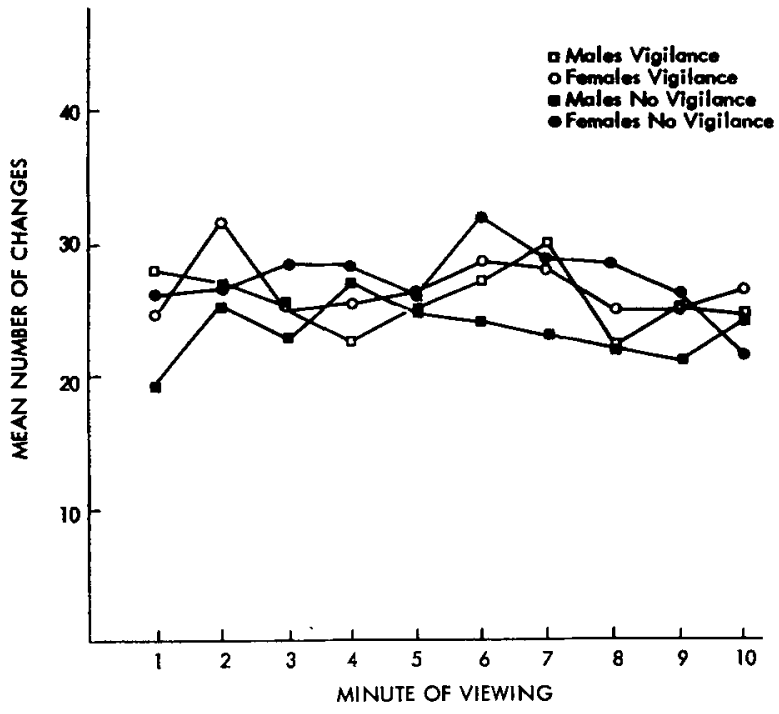

Fig. 1. Mean rivalry rate per minute during $10 \mathrm{~min}$. of massed viewing.

changes was +.68 . That this correlation was no higher suggests that the two measures are indeed somewhat different. Further investigation of the relationship between cycles and changes seems in order. The correlation between blinks and changes for each $S$ ranged from -.75 to +.59 with a mean correlation of +.02 . Only five of the 20 correlations were significant, three negative and two positive. The correlations between blinks and cycles ranged from -.73 to +.48 , with a mean correlation of -.06; only three of these 20 correlations were significant. There seems to be no meaningful relationship between blink rate and rivalry rate.

Examination of the vigilance errors showed rather few errors to have been made overall. Reporting was $95 \%$ accurate and errors did not generally occur coincidentally with decreases in rivalry rate, indicating that decreases in rivalry rate were probably not the result of inattention on the part of the Ss.

Figure 1 shows graphically the number of changes occurring over time in each of the groups. As Fig. 1 suggests, the differences among the groups were not reliable; that is, performance of the rivalry task was not disrupted by simultaneous performance of the vigilance task. The sex effect produced the largest $F$ values $(F=1.12, \mathrm{df}=1 / 16, p>.30)$, the rates of the females being somewhat faster than those of the males; this finding is in line with the report of Goldstein and Cofoid (1965) who found the rates of females to be significantly faster than the rates of males in a large sample. The suggestion of Alexander and Bricker (1952), that Ss with high initial rates show the most extensive decreases in rate with little change in rate for Ss with low initial rates, was not borne out by inspection of the individual graphs. Inspection of 
individual data showed rivalry rates to be variable from moment to moment (mean rate 25.5; mean $\mathrm{SD}$ 6.8) and from $S$ to $S$ (mean rate 25.5; mean SD 4.8).

\section{EXPERIMENT II}

Experiment II examines the rate of binocular rivalry during $10 \mathrm{~min}$. of massed and spaced viewing for viewing periods on three consecutive days. Since no relationship was found in Experiment I between eyeblinks and rivalry rate, no record of eyeblinks was made.

\section{Method}

Subjects. Fifteen male and 15 female students in introductory psychology or anthropology classes served as Ss. Ss were selected who did not wear glasses, were aware of no visual difficulties, and were naive to the rivalry situation.

Procedure. Stimulus, apparatus, and procedure were like those in Experiment I with the following exceptions. Illumination was provided by a $110-\mathrm{V} 25-\mathrm{W}$ bulb in the Telebinocular, producing an overall illumination of $34.7 \mathrm{ft}$.-L as measured by a Gossen LunaSix meter at both eyepieces. Telegraph keys depressions were recorded on an Esterline Angus event recorder. Ss were randomly divided by sex into two groups. All Ss viewed and reported both the rivalry and vigilance tasks for a total of $10 \mathrm{~min}$. per day for three consecutive days. Massed Group Ss viewed continuously for $10 \mathrm{~min}$. on each day. For Spaced Group Ss the $10 \mathrm{~min}$. of viewing was broken into 10 blocks consisting of $1 \mathrm{~min}$. of viewing and $30 \mathrm{sec}$. of relaxing. For all ss the vigilance light was presented every $30 \mathrm{sec}$. on the average. Before each viewing session, the instructions were reviewed. After the third viewing session all Ss were given the Keystone test for binocular acuity and the Keystone fusion test.

\section{Results and Discussion}

Number of changes was counted for 20 Ss during each successive $60-\mathrm{sec}$. unit of each viewing period. Data from four Ss unable to report the vigilance light, four Ss showing differences in binocular acuity of $40 \%$ or more between right and left eyes, and two Ss with identifiable phorias were discarded. The mean number of changes during three consecutive viewing days is shown graphically in Fig. 2. It is apparent in Fig. 2 that during the first minute of viewing on day 1 , during which time both groups were viewing and reporting for the first $1 \mathrm{~min}$. period, rates of Massed and Spaced Groups did not differ. After the first minute of viewing the rates of the Spaced Groups increased, and this increase was maintained throughout the $10 \mathrm{~min}$. viewing period. The initial rate increase has obvious methodological implications for future studies. Except when changes during the first several minutes are of direct interest, data from these first minutes of spaced viewing should be discarded and only data from viewing times following this period of time, during which rivalry rates for Massed Groups were found to be rather stable (see Fig. 2), should be considered.

The Massed Groups showed a smaller initial increase, followed by a decrease to approximately the initial rate level. This interaction between viewing conditions and viewing period was found to be reliable using a Lindquist Type III Analysis of Variance ( $F=$ 2.69, $\mathrm{df}=9 / 144, \mathrm{p}<.01$ ). These results are in agreement with the findings of Aafjes, Hueting, and Visser (1966). Data from the Massed Groups, day 1, provide a replication of the data from the Vigilance Groups, shown in Fig. 1. The only difference between these comparable groups is the elevated rates of male Ss in Fig. 2 during the second and third min. of viewing.

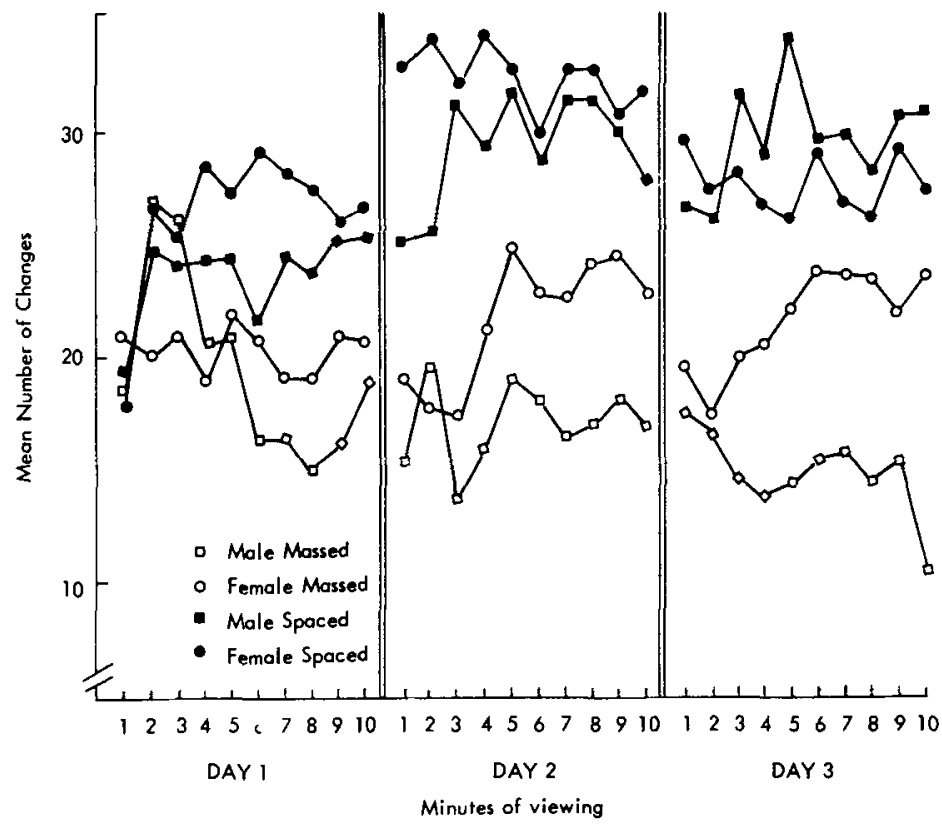

Fig. 2. Mean number of changes per min. during $10 \mathrm{~min}$. of viewing on 3 viewing days. 
The elevated rivalry rates of the Spaced Groups on day 1 were maintained on days 2 and 3 (Fig. 2). The differences between the rates of the Massed and the Spaced Groups were reliable on both days ( $F=6.0$, $\mathrm{df}=1 / 16, \mathrm{p}<.05$ and $\mathrm{F}=4.3, \mathrm{df}=1 / 16, \mathrm{p}<.06$, respectively). No other differences were reliable. This sustained separation of rates between the two groups is surprising. Evidently whatever is responsible for the increases in rate of the Spaced Groups on day 1 continuous to affect rivalry rate as long as 23-hr. after the end of the first and second sessions.

It seems reasonable that such stable changes in rivalry rate may be related to the Ss' problem of how to report partial disappearances of stimulus-halves (fragmentation). When questioned after the final viewing period, every $\mathbf{S}$ acknowledged that he saw some partial disappearances and that he was unsure about how to report them. Decision making about the reporting of fragmentation may have been influenced by motivational factors. Comments from several $\mathrm{Ss}$ in the Spaced Groups suggested that they thought the interviewing intervals, called "rest periods," had been provided by $E$ in order to eliminate eye strain of Ss. This felt concern of $\mathrm{E}$ may have been a motivating factor for Spaced Groups Ss. Since speed of performance has often been found to be a positively valued trait for college populations, the increased motivation postulated could have affected decisions of Spaced Groups Ss about the reporting of fragmentations. If the Spaced Groups tended more than the Massed Groups to report fragmentations as alternations, the durable rate increase of the Spaced Groups would be expected. Certainly further investigations will be needed to explore this hypothesis.

\section{References}

Aafjes, Marlene, Heuting, J. E., \& Visser, P. Individual and interindividual differences in binocular retinal rivalry in man. Psychophysiology, 1966, 3, 19-22.

Alexander, L. T., \& Bricker, P. D. Figure-ground contrast and binocular rivalry. J. exp. Psychol., 1952, 44, 452-454.

Goldstein, A. G., \& Cofoid, Dianne. A developmental study of retinal rivalry. Percept. mot. Skills, 1965, 20, 235-238.

Levelt, w. J. M. On binocular rivalry. Soesterbert, The Netherlands: Institute for Perception RVO-TNO, 1965.

Platz, A., Uhr, L., \& Miller, J. G. A pilot experiment on the effects of meprobomate on stereoscopic retinal rivalry. Percept. mot. Skills, 1960, 10, 230-233.

Washbum, M. F., \& Gillette, A. Studies from the Psych. Lab. of Vassar College: LXII. Motor factors in voluntary control of cube perspective fluctuations and retinal rivalry fluctuations. Amer. J. Psychol., 1933, 45, 315-319.

\section{Notes}

1. This investigation is based on a thesis submitted by the senior author in partial fulfillment of the requirements for the M. A. degree at the University of Missouri.

2. Now at Texas Technological College, Lubbock, Texas.

(Accepted for publication February 2, 1967.) 